\title{
Horizon scanning for translational genomic research beyond bench to bedside
}

\author{
Mindy Clyne, $\mathrm{MHS}^{1,2}$, Sheri D. Schully, PhD², W. David Dotson, PhD³, Michael P. Douglas, $\mathrm{MS}^{3,4}$, \\ Marta Gwinn, MD, MPH ${ }^{3,4}$, Katherine Kolor, PhD ${ }^{3}$, Anja Wulf ${ }^{3,5}$, M. Scott Bowen, MPH ${ }^{3}$ \\ and Muin J. Khoury, MD, PhD2,3
}

Purpose: The dizzying pace of genomic discoveries is leading to an increasing number of clinical applications. In this report, we provide a method for horizon scanning and 1 year data on translational research beyond bench to bedside to assess the validity, utility, implementation, and outcomes of such applications.

Methods: We compiled cross-sectional results of ongoing horizon scanning of translational genomic research, conducted between 16 May 2012 and 15 May 2013, based on a weekly, systematic query of PubMed. A set of 505 beyond bench to bedside articles were collected and classified, including 312 original research articles; 123 systematic and other reviews; 38 clinical guidelines, policies, and recommendations; and 32 articles describing tools, decision support, and educational materials.
Results: Most articles (62\%) addressed a specific genomic test or other health application; almost half of these $(n=180)$ were related to cancer. We estimate that these publications account for $0.5 \%$ of reported human genomics and genetics research during the same time.

Conclusion: These data provide baseline information to track the evolving knowledge base and gaps in genomic medicine. Continuous horizon scanning of the translational genomics literature is crucial for an evidence-based translation of genomics discoveries into improved health care and disease prevention.

Genet Med advance online publication 9 January 2014

Key Words: genomic medicine; horizon scanning; public health; surveillance; translational research

\section{INTRODUCTION}

Genomics and related fields are becoming increasingly relevant in clinical practice for a wide variety of settings, including the deployment of next-generation sequencing in specific scenarios. ${ }^{1,2}$ However, the "arrival" of genomics to the bedside in its current state represents only the initial part of the translational highway. ${ }^{3}$ Genomic research falls on a continuum of four translational phases beyond initial discovery (T0): T1, developing candidate health applications; T2, evaluating candidate health applications and developing evidence-based recommendations; T3, integrating evidence-based recommendations into care and prevention; and T4, assessing health outcomes and population impact. ${ }^{4}$ Our notion of this translation highway is highly idealized. ${ }^{3}$ A more realistic expectation would be that interventions of putative value will enter clinical practice and only over time will enough evidence be accumulated to support evidence-based guidelines.

Research beyond bench to bedside (T2-T4) supports the evaluation of clinical validity and utility of promising applications, in addition to research on comparative effectiveness, implementation, and outcomes, to achieve population health benefits. ${ }^{4}$ The history of medicine teaches us that premature implementation of promising new technologies without meeting an evidentiary threshold can lead to potential harms and increasing health-care costs. ${ }^{3}$ Yet almost all current published research in human genomics is in the discovery or the "bench to bedside" phase. A previous PubMed analysis found that less than $1 \%$ of the published literature on human genomics was related to phases T2 or beyond. ${ }^{4}$ This trend follows closely the current level of funding in human genomics research by the National Cancer Institute (only $2 \%$ of human genomics research funding goes to $\mathrm{T} 2$ or beyond). ${ }^{5}$

Since 2012, the Office of Public Health Genomics, in collaboration with the National Cancer Institute, has been regularly tracking the translational genomics research scientific literature to develop a current baseline for the field and to identify opportunities, gaps, and challenges in genomic medicine. Herein, we briefly summarize the 1-year data and discuss a process for integrated horizon scanning of research that can inform research, policy, and practice.

\section{MATERIALS AND METHODS}

Each week, the Office of Public Health Genomics of the Centers for Disease Control and Prevention publishes the free Genomics and Health Impact Update newsletter online and delivers it by e-mail to more than 50,000 subscribers worldwide. ${ }^{6}$ Horizon scanning for translational research in this weekly update includes a PubMed targeted search query, supplemented by monitoring of online news using Google Alerts and

${ }^{1}$ Kelly Services, Troy, Michigan, USA; ${ }^{2}$ Epidemiology and Genomics Research Program, National Cancer Institute, Bethesda, Maryland, USA; ${ }^{3}$ Office of Public Health Genomics, Centers for Disease Control and Prevention, Atlanta, Georgia, USA; ${ }^{4} \mathrm{McKing}$ Consulting Corporation, Atlanta, Georgia, USA; ${ }^{5} \mathrm{Cadence}$ Group, Atlanta, Georgia, USA.

Correspondence: Mindy Clyne (mindy.clyne@nih.gov) 
Table 1 Classification and examples of products identified by horizon scanning for the CDC Genomics and Health Impact Weekly Update showing translational phase groupings by product type

T0/T1

Discovery, characterization, and development

\begin{tabular}{|c|c|c|c|}
\hline \multicolumn{2}{|l|}{ Original studies } & \multicolumn{2}{|c|}{$\begin{array}{l}\text { GWAS, biomarkers, and proposed } \\
\text { new applications }\end{array}$} \\
\hline \multicolumn{2}{|c|}{$\begin{array}{l}\text { Research synthesis/modeling/ } \\
\text { meta-analysis/systematic reviews/ } \\
\text { narrative reviews }\end{array}$} & \multicolumn{2}{|c|}{$\begin{array}{l}\text { Meta-analysis and systematic } \\
\text { reviews of gene-disease } \\
\text { associations }\end{array}$} \\
\hline \multicolumn{2}{|l|}{$\begin{array}{l}\text { Guidelines/policies/ } \\
\text { recommendations }\end{array}$} & \multicolumn{2}{|c|}{$\begin{array}{l}\text { New nomenclature, data sharing, } \\
\text { and publication standards }\end{array}$} \\
\hline \multicolumn{2}{|c|}{$\begin{array}{l}\text { Tools/methods/training/education/ } \\
\text { decision support }\end{array}$} & \multicolumn{2}{|c|}{$\begin{array}{l}\text { Research road maps, databases, } \\
\text { software, and training tools }\end{array}$} \\
\hline \multicolumn{4}{|c|}{$\begin{array}{l}\text { CDC, Centers for Disease Control and Prevention; GWAS, genome-wide associat } \\
\text { Table } 2 \text { Number of publications and specific examples } \\
\text { from horizon scanning for the CDC Genomics and Health } \\
\text { Impact Weekly Update (16 May } 2012 \text { to } 15 \text { May 2013) }\end{array}$} \\
\hline & $\mathrm{T} 2$ & \multicolumn{2}{|l|}{ T3-T4 } \\
\hline & $\begin{array}{l}\text { What works? } \\
\text { (example } \\
\text { reference) }\end{array}$ & $\begin{array}{l}\text { How is it } \\
\text { implemented and } \\
\text { is it working? } \\
\text { (example } \\
\text { reference) }\end{array}$ & Total \\
\hline Original research & 106 (ref. 7) & 206 (ref. 8) & 312 \\
\hline $\begin{array}{l}\text { Knowledge } \\
\text { synthesis }\end{array}$ & 83 (ref. 9) & 40 (ref. 10) & 123 \\
\hline $\begin{array}{l}\text { Guidelines/policies/ } \\
\text { recommendations }\end{array}$ & 27 (ref. 11) & 11 (ref. 12) & 38 \\
\hline $\begin{array}{l}\text { Tools/methods/ } \\
\text { training/education/ } \\
\text { decision support }\end{array}$ & 8 (ref. 13) & 24 (ref. 14) & 32 \\
\hline Total & 224 & 281 & 505 \\
\hline
\end{tabular}

CDC, Centers for Disease Control and Prevention.

genomics-related websites. Publications collected by this process are reviewed and classified by two or more coders according to the schema in Table 1. In this brief report, we limit our analysis and presentation only to articles identified in PubMed beyond bench to bedside phases (T2-T4). Because of the small number of publications in some categories, we group the products into two clusters: T2 (what works?) and T3-T4 (how has it been implemented and is it working in the real world?).

\section{RESULTS}

During the 1-year period from 16 May 2012 to 15 May 2013, 505 beyond bench to bedside articles were identified in PubMed. Of these, $44 \%$ were classified as T2 research and $56 \%$ as T3 or T4 reports (Table 2). There were 312 original research articles; 123 reviews; 38 articles describing clinical guidelines, policies, and recommendations; and 32 describing tools, decision support, and educational materials. The Supplementary Appendix online shows a list of published
T2

T3/T4

Evaluation of tests and interventions

Clinical trials, clinical cohorts, and new data on analytic or clinical validity

Evidence reports

Clinical practice and professional guidelines

Modeling methods, databases, and methods for systematic review
Implementation in practice and programs

Studies generating new process or outcome data from clinical populations; surveillance

Cost-effectiveness analyses and national program evaluation

Electronic health standards, reporting requirements, and ethical standards

Clinical algorithms; provider and patient education materials

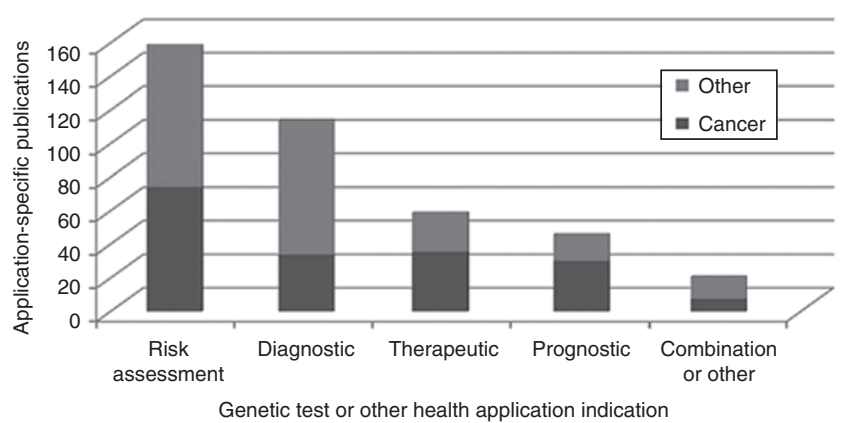

Figure 1 Horizon scanning publications that addressed a specific genomic test or health application, by indication, with proportion related to cancer (16 May 2012 to 15 May 2013).

articles describing guidelines, policies, and recommendations, by topic and source. Not included here are seven additional policies and guidelines that were not listed in PubMed during the horizon scan (e.g., US Food and Drug Administration, Centers for Medicare \& Medicaid Services, European Union's Genetic Testing Panel, and UK Human Genetics Commission).

Table 2 also shows specific examples of the types of translational research publications by category. ${ }^{7-14}$ More than three-fourths of these publications $(n=399)$ addressed a specific genetic test or other health application; almost half of these $(n=180)$ were related to cancer. The next largest categories were hereditary disorders (21\%), cardiovascular disease (11\%), and birth defects (6\%). Figure 1 summarizes application-specific publications by indication, along with the proportion in each group related to cancer.

Cancer represented 45\% (180/399) of all articles referencing a specific genetic test or genomic technology in the T2-T4 space. One-third of cancer genetic testing and genomic technology articles were related to risk assessment, followed by $19 \%$ therapeutic, $18 \%$ diagnostic, $16 \%$ prognostic, $7 \%$ preventive, and $2 \%$ population screening, with the remaining $4 \%$ addressing a combination of these. Germ-line testing 
(including use of family history tools) was the focus in 63\% of articles addressing cancer genetic testing and genomic technologies. Somatic testing represented $36 \%$, including five articles that overlapped germ-line and somatic testing. Forty-nine percent $(88 / 180)$ of the cancer genetic testing and genomic technology articles were classified as T2 and 51\% (92/180) were classified as T3.

Family history tools and methods represented 7\% of all articles in our collection, subcategorized as T2 $(n=10)$ or T3-T4 $(n=25)$. Sixteen percent $(n=82)$ of all articles addressed pharmacogenomic testing. Almost half of the pharmacogenomic articles were related to cancer.

\section{DISCUSSION}

In this brief report, we present baseline data on an ongoing horizon scanning by the Office of Public Health Genomics of the Centers for Disease Control and Prevention, in collaboration with the National Cancer Institute, of the translational genomics research scientific literature. This public health surveillance activity identifies promising genomic applications for clinical practice and knowledge gaps that necessitate additional research. Before commenting on these findings, it is important to acknowledge the limitations of this analysis. First, in spite of our systematic effort to capture the pertinent literature, our PubMed queries had imperfect sensitivity and specificity. Although we have steadily improved specificity through manual curation by multiple reviewers, it is difficult to quantify accurately the number of missed items. These baseline data can be used to continue to improve search capacity using machine learning tools. We will continue to refine the use of online search tools to capture research that is not published, or is published only in abstracts from scientific meetings, websites, or online databases, or the "gray" literature. During the 1-year period that we analyzed, such searches identified 15 additional items, including the 7 additional guidelines and policies. These are probably only a subset of those discoverable online. Finally, we should note that publications in a given year represent the results of research initiated in previous years. To feel the pulse of translational research in genomic medicine, it is important to integrate these analyses with existing databases of clinical trials, genetic testing information, and ongoing research funding by the National Institutes of Health and other institutions. ${ }^{5}$

We present these data as a baseline survey of post bench to bedside translational research in genomic medicine. They provide a starting point for future horizon scanning and a foundation for future enhancements as suggested above. This research represents only a small fraction of publications in human genetics and genomics. Although we cannot get an accurate estimate of the denominator for such research during the period of horizon scanning, a search of PubMed for genetics and genomics research in humans yielded almost 95,000 published articles in 2012. Therefore, we estimate that the number of T2-T4 publications presented here is about half a percent of all published human genetics and genomics research. These data are consistent with previous analyses conducted in the 2000s for general human genetics research and specifically for cancer. ${ }^{4,5}$ It is not clear what percentage of all genomic research should be distributed across T2, T3, and $\mathrm{T} 4$ because genomic medicine is still a rapidly moving discovery field. As the field matures, we expect an increasing proportion of research to be conducted and published in later phases of translation.

It is interesting to note that, even in the rapidly developing field of genomic medicine, 38 articles describing guidelines, policies, and recommendations were published in a single year (see Supplementary Appendix online). These articles covered a wide range of topics, including newborn screening, prenatal testing, pharmacogenomics, cancer, and other fields. Surveillance efforts such as the one presented here will become even more important in the near future, as additional guidelines and recommendations are developed for new genomic applications.

The Office of Public Health Genomics of the Centers for Disease Control and Prevention continues to track new or emerging health applications of genomic research through the GAPPFinder, ${ }^{15}$ which is an integral part of the online Genomic Applications in Practice and Prevention Knowledge Base (GAPP KB). ${ }^{16}$ As part of GAPP KB, we classify genomic applications according to the maturity of evidence and readiness for use in routine clinical practice (according to a three-tier classification system). ${ }^{17}$ These efforts, along with the newly launched National Institutes of Health Genetic Testing Registry, ${ }^{18}$ will help capture, over time, a more complete picture of the existing evidence on validity and utility of emerging genomic applications and the body of T2-T4 research that supports their use in practice. This evolving body of information will inform researchers, practitioners, patients, and policy makers.

In summary, continued horizon scanning helps identify and monitor translational research that addresses the evaluation, implementation, and health impact of genomic applications. An especially important area is cancer prevention and treatment, where some of this research funded by the National Cancer Institute is already in progress. ${ }^{19}$ We also expect that recent funding by the National Human Genome Research Institute for pilot demonstration projects ${ }^{20}$ will increase the amount of information available for informed decision making on implementation and impact of genomic medicine. Other stakeholders and organizations, both private and public, are likely to benefit from increasing emphasis on translational research. ${ }^{21}$

\section{SUPPLEMENTARY MATERIAL}

Supplementary material is linked to the online version of the paper at http://www.nature.com/gim

\section{DISCLOSURE}

The authors declare no conflict of interest. The findings and conclusions in this report are those of the authors and do not necessarily reflect the views of the Department of Health and Human Services. 


\section{REFERENCES}

1. Green ED, Guyer MS; National Human Genome Research Institute. Charting a course for genomic medicine from base pairs to bedside. Nature 2011;470:204213.

2. Manolio TA, Chisholm RL, Ozenberger $B$, et al. Implementing genomic medicine in the clinic: the future is here. Genet Med 2013;15:258-267.

3. Evans JP, Khoury MJ. The arrival of genomic medicine to the clinic is only the beginning of the journey. Genet Med 2013;15:268-269.

4. Khoury MJ, Gwinn M, Yoon PW, Dowling N, Moore CA, Bradley L. The continuum of translation research in genomic medicine: how can we accelerate the appropriate integration of human genome discoveries into health care and disease prevention? Genet Med 2007;9:665-674.

5. Schully SD, Benedicto CB, Gillanders EM, Wang SS, Khoury MJ. Translational research in cancer genetics: the road less traveled. Public Health Genomics 2011;14:1-8

6. Centers for Disease Control and Prevention, Office of Public Health Genomics, Genomics \& Health Impact Update [Online]. http://www.cdc.gov/genomics/ update/current.htm Accessed 22 August 2013.

7. Lansky A, Elashoff MR, Ng V, et al. A gender-specific blood-based gene expression score for assessing obstructive coronary artery disease in nondiabetic patients: results of the Personalized Risk Evaluation and Diagnosis in the Coronary Tree (PREDICT) trial. Am Heart J 2012;164:320-326.

8. Reid RJ, McBride CM, Alford SH, et al. Association between health-service use and multiplex genetic testing. Genet Med 2012;14:852-859.

9. Azim HA Jr, Michiels S, Zagouri F, et al. Utility of prognostic genomic tests in breast cancer practice: the IMPAKT 2012 Working Group Consensus Statement. Ann Oncol 2013;24:647-654.

10. Potter BK, Chakraborty P, Kronick JB, et al.; Canadian Inherited Metabolic Diseases Research Network. Achieving the "triple aim" for inborn errors of metabolism: a review of challenges to outcomes research and presentation of a new practice-based evidence framework. Genet Med 2013;15:415-422
11. Wilke RA, Ramsey LB, Johnson SG, et al.; Clinical Pharmacogenomics Implementation Consortium (CPIC). The clinical pharmacogenomics implementation consortium: CPIC guideline for SLCO1B1 and simvastatininduced myopathy. Clin Pharmacol Ther 2012;92:112-117.

12. Monaghan KG, Benkendorf J, Cherry AM, et al. ACMG Policy Statement. Risk categorization for oversight of laboratory-developed tests for inherited conditions. Genet Med 2013;15:314-315.

13. Nguyen TT, Schäfer H, Timmesfeld N. Making medical decisions in dependence of genetic background: estimation of the utility of DNA testing in clinical, pharmaco-epidemiological or genetic studies. Genet Epidemiol 2013;37:311322.

14. Baer HJ, Schneider LI, Colditz GA, et al. Use of a web-based risk appraisal tool for assessing family history and lifestyle factors in primary care. J Gen Intern Med 2013;28:817-824.

15. Gwinn M, Grossniklaus DA, Yu W, et al. Horizon scanning for new genomic tests. Genet Med 2011;13:161-165.

16. GAPP KB (Genomic Applications in Practice and Prevention Knowledge Base) Atlanta. Centers for Disease Control and Prevention, Office of Public Health Genomics 2010. http://www. hugenavigator.net/GAPPKB/home.do.

17. CDC Office of Public Health Genomics: Genomic Tests and Family History by Levels of Evidence. http://www.cdc.gov/genomics/gtesting/tier.htm Accessed 22 August 2013.

18. Rubinstein WS, Maglott DR, Lee JM, et al. The NIH genetic testing registry: a new, centralized database of genetic tests to enable access to comprehensive information and improve transparency. Nucleic Acids Res 2013;41:D925-D935.

19. Simonds NI, Khoury MJ, Schully SD, et al. Comparative effectiveness research in cancer genomics and precision medicine: current landscape and future prospects. J Nat/ Cancer Inst 2013;105:929-936.

20. National Human Genome Research Institute: Research funding news. http:// www.genome.gov/ResearchFunding/ Accessed 22 August 2013.

21. Khoury MJ, Feero WG, Reyes M, et al.; GAPPNet Planning Group. The genomic applications in practice and prevention network. Genet Med 2009;11:488-494. 